\title{
sciendo
}

CIVIL AND ENVIRONMENTAL ENGINEERING REPORTS

E-ISSN 2450-8594

CEER 2021; 31 (3): 0177-0196

DOI: $10.2478 /$ ceer-2021-0040

Original Research Article

\section{EFFECT OF MODIFIED CARBON NANOTUBES EPOXY ON THE MECHANICAL PROPERTIES OF CONCRETE REINFORCED WITH FRP SHEETS}

\author{
Hamid KAZEMI ${ }^{1}$, Mostafa HEYDARI ${ }^{1}$, Fateme Farash BAMOHARAM ${ }^{2}$ \\ ${ }^{1}$ Department of Civil Engineering, Islamic Azad University, Mashhad Branch, Mashhad, \\ Iran \\ ${ }^{2}$ Department of Chemistry, Islamic Azad University, Mashhad Branch, Mashhad, Iran
}

\begin{abstract}
Today, using Fiber Reinforced Polymer (FRP) sheets is one of the conventional methods in retrofitting concrete structures. Some factors affecting FRP sheets proper performance include mechanical properties, surface specifications, connector's material and connecting approach in concrete elements. Previous studies showed that FRP epoxy resin and its basic surface have a significant impact on the ultimate bearing capacity. In line with the development of nanotechnology in recent years, this paper presents an experimental study to show the effects of adding the best percentage of nano-carbons to adhesive resin and evaluate the ultimate axial, shear and bending strengths in concrete samples. The results show that using FRP with carbon nanotube reinforced resins will significantly increase stiffness and ductility by $100 \%$; moreover, it shows an effective increase of almost $13 \%$ in axial and flexural strengths of specimens.
\end{abstract}

Keywords: carbon nanotube, epoxy resin, fiber reinforced polymer, mechanical properties, mechanical testing

\footnotetext{
${ }^{1}$ Corresponding author: Department of Civil Engineering, Islamic Azad University, Mashhad Branch, Mashhad, Iran, e-mail: hamid.kazemi@srbiau.ac.ir
} 


\section{INTRODUCTION}

Improving the structural safety against the loads has always been one of the significant issues for structural engineering in existing structures and future ones. For new structures, the current regulations define designing and construction methods in details; but ensuring the safety of the existing structures has many difficulties including unknown parameters, high uncertainties, various construction methods and economic aspects.

One of the conventional methods in the retrofitting existing buildings is using FRP which can increase the loading capacity of its members up to an acceptable level. Some of the advantages of FRP sheets are high strength to weight ratio, high durability against corrosion and ease of implementation or installation [1]. The use of FRP usually improves the shear and bending capacity of members simultaneously and creates better properties than traditional methods such as increasing cross-section of concrete members or using jacket steel plates according to architecture considerations [2].

Epoxy resins are used as a material for gumming fiber sheets and adding these sheets to the concrete surface. The resins are responsible for transferring forces between the old concrete surface and the FRP surface. Various experimental studies have shown that the lack of suitable bonding between FRP and concrete were the leading cause of failure in FRP reinforced concrete structures, so usually the ultimate performance of the system depends on these bonds [3].

Many researchers worked on FRP and Carbon Fiber Reinforced Polymer (CFRP) and their impact on improving stiffness, strength and ductility. Teng and Lam (2002) investigated the behavior of confined elliptical column [4]; Park et al. (2008) examined the effects of surroundings on FRP narrow strips [5]; Diego et al. (2015) worked on circular column reinforced by FRP [6]; Dong et al. (2012) and Mahal (2015) studied the fatigue behavior of concrete beams with FRP and CFRP. The results showed that the FRP sheets significantly increased the fatigue resistance the ultimate strength and ductility of the beams $[7,8]$. Ferrari et al. (2013) tried to investigate concrete beams with high performance fiber reinforced cementitious composites and CFRP [9]. Cristina et al. (2013), Faruqi et al. (2013) and Naderi and Esmaelizade (2013) examined the effect of temperature/fire on adhesion of CFRP concrete. They, using the numerical and the experimental study, indicated that the materials properties are also seriously affected the mode of shear failures at very low and high temperatures [10-12].

Kheireddine et al. (2011) and Zheng et al. (2012) investigated concrete slabs reinforced with FRP or GFRP. The experimental and numerical results indicated the effect of FRP and GFRP on ultimate strengths, compressive membrane action and punching shear [13-15].

In recent years, with the application of nanotechnology (aims to change the manipulation of atoms or molecules), it is possible to ensure the effectiveness and efficiency of materials. The nature of nanotechnology is related to the ability to 
work in atomic, molecular, and ultra-molecular levels at the scale of nanometers. Factors that make nanomaterials different from other materials are increased surface area and quantum effects. These factors affect properties such as reactivity, strength, electrical property and in vivo behavior $[16,17]$.

Many investigations were performed about the effect of carbon nanotubes (CNTs) on mechanical properties of epoxies. These were aimed to investigate thermal properties, fibre orientation effect, compressive strengths of epoxy nanocomposites, various loadings, different types of CNTs and different types of laminates.

Rosso et al. (2006) and Tsai and Cheng (2009) showed that the addition of silicananoparticles improved the stiffness/toughness of an epoxy resin $[18,19]$. In the work of Godara et al., it was specified that with the presence of CNTs in the matrix, the coefficient of thermal expansion decrease by $32 \%$ and there is also a substantial increase in fracture toughness mode-1 by over $80 \%$ [20]. Greef et al. (2011) investigated the development of damage in a woven carbon fiber/epoxy composite. The most important results were the hindering effect of CNTs on the formation of transverse cracks [21]. Phong's tests showed that with $0.1 \mathrm{wt} . \%$ of nanoparticles, the fracture toughness was significantly improved by $\sim 70 \%$ and the fatigue life increased 10-30 times longer than those of the unmodified composite [22]. The effect of different modified nano- $\mathrm{CaCO}_{3}$ content on the epoxy resin was studied by Zhang et al. (2013) and the compression test revealed a sizeable improvement of $13.5 \%, 6.1 \%, 42.5 \%$ and $106.3 \%$ in compressive strength, elastic modulus, displacement and the total fracture work of epoxy resin cast, respectively, filled with 4 wt.\% nano-CaCO3 [23]. Shirkavand et al. (2013) evaluated the mechanical properties of Multi-Walled Carbon Nano-Tubes (MWCNTs) and increased young's modulus, tensile strength and fracture strain resulted [24]. Sanchez et al. (2013) performed a research on epoxy matrices modified with different CNTs contents and surface conditions using a calendering method [25]. Liu et al. (2017) showed that rigid nanoparticles had evident strengthening effects on both the compression and flexural responses [26].

Focusing on bonding effect researches, Zhou et al. (2013) performed their research on strengthening reinforced concrete beams with friction hybrid bonding techniques; Diab and Ferghal (2014) performed a laboratory study to predict the bond strength and the effective bond length of FRP sheets/plates considering the type and properties of the adhesive layer; Korayem et al. (2015) examined the effect of CNT modified epoxies on the adherence of CFRP and steel composites; Irshidat and al-Saleh (2016) reviewed the effect of using modified CNTs to reduce bond-slip. Experimental results generally showed that using CNT modified epoxy resin enhanced the bond strength and ultimate slippage and affected epoxy type, fiber sheet type, FRP bond length, and FRP bond width. [27-30]. 
It is known that different failure modes of FRP reinforced beams happen in the brittle mode that even have no signs. There are two significant failure modes [31]: 1) Failure occurs in the adhesive layer (epoxy); this is very common and may accompany by removal of the concrete cover. These detachments, start from the corner sheet and gradually expand; 2) Failure occurs in the concrete; cracks will cause detachment in some parts of the composites. Detachment mechanism is a result of stress concentration at the end of FRP or near existing cracks in concrete and it will generally begin from inside of the concrete, surface FRPs or the site of flexural reinforcement.

So various studies show that adding CNTs to epoxy with carbon fiber composites can significantly improve the contact mechanical specifications. It means that while the sheet separates from the concrete surface, the concrete strength increases, so a higher volume of concrete contribute with FRP fibers [32].

Since it seems that with improvements in the performance of epoxy, the mechanism of load path between the different layers and the efficiency will increase, in this paper a new experimental research is performed using CNTs in epoxy as an adhesive agent and focusing on the integrated performance of concrete component and FRP, the mechanical strength of specimens such as axial strength, flexural strength and shear strength and the applied results were obtained. In fact, the objective of present paper is to exclusively evaluate the mechanical/structural properties after adding CNTs to epoxy.

\section{MATERIALS}

Materials used in the laboratory tests were: concrete, FRP, pure resins, carbon nano-fiber reinforced resin, primers and putty.

\subsection{Concrete}

Two types of concrete with compression strengths of 20 and $40 \mathrm{MPa}$ were used in the tests with certain mixing percentage according to Table 1 and Fig. 1. The cubic/cylindrical specimens prepared based on ISO 4012: 1978 [33] and prismatic specimens for bending tests (fine-grained concrete) made ready according to ASTM C348-02 [34].

Table 1. Amount of cement, sand, aggregate and water in different grades of concrete

\begin{tabular}{|l|l|l|}
\hline Concrete Grades & A & B \\
\hline Expected strength $(\mathrm{MPa})$ & 20 & 40 \\
\hline Existed strength $(\mathrm{MPa})$ & 20.3 & 40.8 \\
\hline Coarse aggregate $(\mathrm{d}: 12-25 \mathrm{~mm})\left(\mathrm{kg} / \mathrm{m}^{3}\right)$ & 373 & 331 \\
\hline Fine aggregate $(\mathrm{d}: 5-12 \mathrm{~mm})\left(\mathrm{kg} / \mathrm{m}^{3}\right)$ & 381 & 338 \\
\hline Sand $(\mathrm{dmax}: 5 \mathrm{~mm})\left(\mathrm{kg} / \mathrm{m}^{3}\right)$ & 1120 & 995 \\
\hline Cement $\left(\mathrm{kg} / \mathrm{m}^{3}\right)$ & 275 & 458 \\
\hline Water $\left(\mathrm{kg} / \mathrm{m}^{3}\right)$ & 204 & 241 \\
\hline Fresh concrete density $\left(\mathrm{kg} / \mathrm{m}^{3}\right)$ & 2360 & 2370 \\
\hline
\end{tabular}




\subsection{Fiber Reinforced Polymer (FRP)}

FRP is a composite material with high tension strength made of a polymer matrix reinforced with glass, carbon, aramid, kevlar or basalt fibers. The polymer is usually an epoxy, vinyl ester or polyester thermosetting plastic, though phenol formaldehyde resins are still in use [35].

Table 2 shows the exact characteristics of FRP sheets (glass fiber) that were obtained by experimental tests based on ASTM D3039-17 standard [36].

Table 2. Characteristics of the FRP sheets

\begin{tabular}{|l|l|l|}
\hline No. & Property & Value \\
\hline 1 & The primary fiber direction & Zero degrees, unidirectional \\
\hline 2 & Tensile strength $(\mathrm{MPa})$ & 2310 \\
\hline 3 & Tensile modulus $(\mathrm{GPa})$ & 91 \\
\hline 4 & Elongation at break $(\%)$ & 3.9 \\
\hline 5 & Density $\left(\mathrm{g} / \mathrm{cm}^{3}\right)$ & 2.54 \\
\hline 6 & Area weight $\left(\mathrm{g} / \mathrm{m}^{2}\right)$ & 203 \\
\hline 7 & Thickness $(\mathrm{mm})$ & 0.078 \\
\hline
\end{tabular}

\subsection{Epoxy Resins}

FRPs are bonded to the reinforced concrete members generally using an epoxy resin to provide additional tensile/confining reinforcement. They should have the following properties: compatibility and adhesion to the concrete surface and FRP; environmental resistance (chemical and heat); filling property and durability and high performance. So epoxy resin is used in two ways in this research: 1) pure resin, 2) Carbon Nano-Fiber Reinforced Resin.

\subsubsection{Pure Resin}

"Sikadur 330" resins (Turkish made) which have two components: a) pure white resin (part A), and b) grey hardener (part B). According to manufacturer's specifications, the mixing ratio of 4 is recommended, it means that "part $A$ " is used 4 times more than "part B".

The initial set time and composition hardening time are approximately 1 hour and 4-5 hours, respectively. Compression strength and mechanical properties are given in tables 3 and 4 considering temperature and age.

Table 3. Compression strength of sikadur-330 resins at different temperatures

\begin{tabular}{|l|l|l|l|l|}
\hline Composition age /temperature & $4^{\circ}$ & $16^{\circ}$ & $23^{\circ}$ & $32^{\circ}$ \\
\hline 8 hours & - & - & - & 55.2 \\
\hline 1 days & - & 55.8 & 73.7 & 73.1 \\
\hline 3 days & 55.8 & 77.2 & 76.5 & 75.8 \\
\hline 7 days & 77.2 & 80 & 77.2 & 81.3 \\
\hline 14 days & 86.2 & 85.5 & 81.3 & 82 \\
\hline
\end{tabular}


Table 4. Mechanical properties of sikadur-330 resins at the age of 7 days

\begin{tabular}{|l|l|l|}
\hline No. & Property & Values \\
\hline 1 & Tensile strength $(\mathrm{MPa})$ & 33.8 \\
\hline 2 & Elongation $(\%)$ & 1.2 \\
\hline 3 & Bending strength $(\mathrm{MPa})$ & 60.6 \\
\hline 4 & Bending modulus $(\mathrm{MPa})$ & 3.48 \\
\hline
\end{tabular}

\subsubsection{Carbon Nano-Fiber Reinforced Resin}

In CNTs, atoms of carbon are arranged in a cylindrical structure. In fact, they are graphite in the form of pipes. In graphite, regular carbon hexagonal plates are gathered to make graphite plates; however, in CNTs, carbon plates stacked on each other and each layer is connected to the substrate through weak van der waals bonds [37].

Adding CNTs reinforce the material characteristics such as tensile strength with low deformation, surface-to-volume, low density and thermal conductivity [17]. Nano-carbons include CNTs and carbon nano-fibers (CNFs), improve bond slip, ultimate tensile stress and young's modulus. So, it is expected that they can prevent the growth initial cracks in concrete $[9,13,14]$.

In this study, multi-walled nanotubes with functionalized $\mathrm{COOH}$ (MWCNT$\mathrm{COOH}$ ) have been used which their physical/mechanical properties are shown in Tables 5. Modified epoxy was prepared by combining MWCNT-COOH, 250 grams of epoxy and 62.5 grams of epoxy hardener according to the manufacturer's instructions. CNTs percentage weight was one of the variables in the test and it was calculated based on the weight of pure white resin, the weight of grey hardener and CNTs percentage weight. 

OF CONCRETE REINFORCED WITH FRP SHEETS

Table 5. Characteristics of used CNTs

\begin{tabular}{|l|l|l|}
\hline No. & Property & Values \\
\hline 1 & Purity & $\begin{array}{l}\text { More than 95\% of CNTs weight and } \\
1.23 \% \text { of COOH weight }\end{array}$ \\
\hline 2 & Particle size & $\begin{array}{l}\text { Inner diameter: } 5-10 \mathrm{~nm} \\
\text { External diameter: } 10-20 \mathrm{~nm}\end{array}$ \\
\hline 3 & Length & Microns $10-30$ \\
\hline 4 & Color & Black \\
\hline 5 & The size of particles in the ash form & Less than $1.5 \%$ of the weight \\
\hline 6 & Electrical conductivity $(\mathrm{s} / \mathrm{cm})$ & 100 \\
\hline 7 & Bulk density $\left(\mathrm{g} / \mathrm{cm}^{3}\right)$ & 0.22 \\
\hline 8 & Specimen density $\left(\mathrm{g} / \mathrm{cm}^{3}\right)$ & 2.1 \\
\hline 9 & Thermal conductivity $(\mathrm{W} / \mathrm{m} \cdot \mathrm{K})$ & 3000 \\
\hline 10 & Electrical conductivity $(\mathrm{s} / \mathrm{m})$ & $10^{5}-10^{7}$ \\
\hline 11 & Young's modulus $(\mathrm{GPa})$ & $\begin{array}{l}\text { SWCNT } \\
\text { Steel:208 }\end{array}$ \\
\hline 12 & Tensile strength $(\mathrm{GPa})$ & $\begin{array}{l}\text { SWCNT:150; MWCNT:150; } \\
\text { Steel:0.4 }\end{array}$ \\
\hline 13 & Density $\left(\mathrm{g} / \mathrm{cm}^{3}\right)$ & MWCNT:2.6; Steel:7.8 \\
\hline
\end{tabular}

* single-walled carbon nanotube

**multi-walled carbon nanotube

\subsection{Primers and Putty}

A primer coat is generally applied as one or two layers on the concrete surface to penetrate its open pores, small voids, cracks or uneven areas. First, the highviscosity polymer putty may be applied using a clean trowel or spatula or any suitable tool as a filler and the second step is to apply a low-viscosity polymer as primer coat to obtain a uniform bondable substrate. The prepared surface should be protected from moisture, dust and other contaminants before FRP installation [38].

\section{LABORATORY TEST METHODS}

The following steps were taken in laboratory: preparation of concrete specimens; initial tests for verification; composition of resin and nano-carbon; optimal value of CNT test; installation of FRP layers on concrete; implementation of pull-off, compression strength and flexural tests. The final test results are separately presented in 4 section. 


\subsection{Verification Tests}

At first, many specimens were made and results were validated with results of other researches, and at the next stage the following tests have been considered. It is noted that the tests were performed while the concrete cylindrical strength reached 20 and $40 \mathrm{MPa}$.

\subsection{Optimal Mixture Percentage of CNT}

\subsubsection{Initial Test on Composition of Resins and Nano-Carbons}

CNTs are typically used as a master batch usually produced by using polystyrene in ultrasonic or magnetic stirrer. Also, CNTs are usually $10 \%$ to $20 \%$ in master batch combinations. So, an initial combination of resin with hardener was made according to the manufacturer's instructions. In this way, 0.5 gr. of CNTs, 8.81 gr. of Sikadur-330 epoxy (part A), 2.65 gr. of polystyrene and 2.65 gr. of hardening epoxy (part B) were selected.

In this composition, nano-carbon epoxy was mixed using magnetic and mechanical stirrers for 15 minutes and then epoxy hardener was added to the composition. After almost 4 hours, overheating and ultimately hardening of the mixture was observed. Then, four different mixing percentage with 3.5, 4.0, 4.5 and 5 of CNTs were selected and so the best weighted percentage of CNT were selected by shear test as described in 4.1 section.

\subsubsection{Mixing of CNT and Resin}

After determining optimal CNTs percentage and curing new mix based on the existing surface, the modified epoxy prototype was created with the following procedure:

To compose a uniform mixing, preheating up to $80^{\circ} \mathrm{C}$ has been performed and epoxy was mixed during 3 minutes with $150 \mathrm{rpm}$ as shown in Fig. 2a. Then, CNTs gradually were added to the epoxy in 10 parts. The entire mixing operation took about 25 minutes and ended up in $350 \mathrm{rpm}$ that uniformity and homogeneity of the resin can be seen in Fig. 2b. Then, the FRP sheets were installed based on ACI 440.2R-08 as shown in Fig. 3.

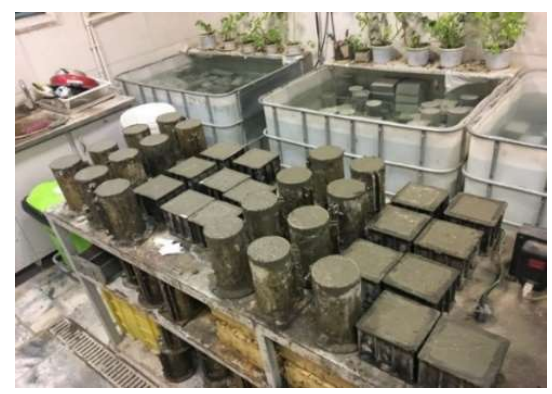

Fig. 1. The cubic/cylindrical concrete specimens 

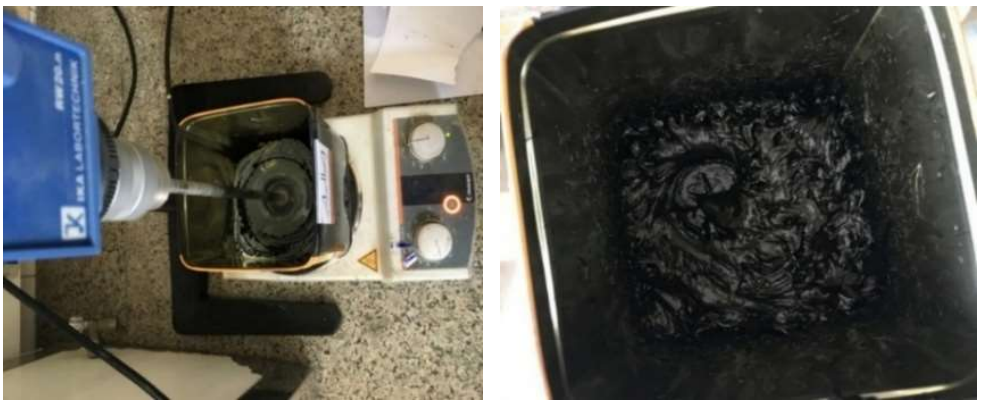

Fig. 2. a) mixing epoxy with CNTs (left), b) modified epoxy (right)
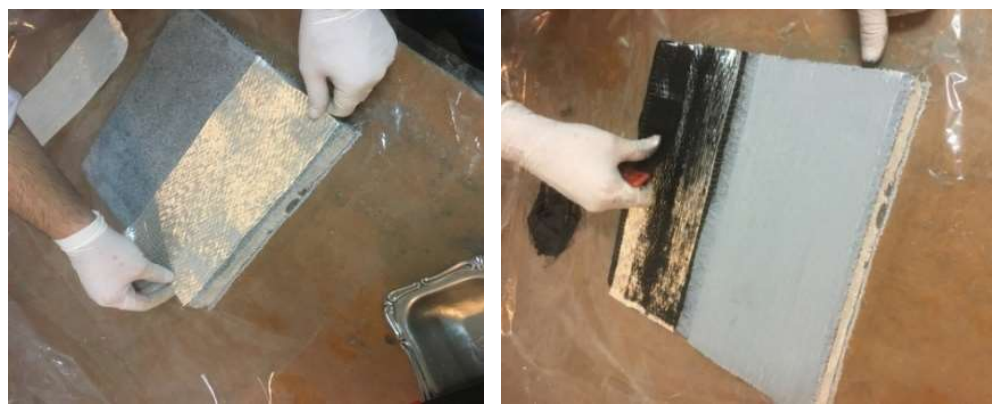

Fig. 3. Installation of FRP on the concrete sheets and removing air pockets by laminate roller

\subsection{Pull-off test}

FRP fiber adhesion to the concrete surface is evaluated by pull-off test according to ASTM C1583. This test is an easy and fast way to determine the characteristics of the most significant vertical force exerted on the concrete surface, FRP and epoxy adhesive [39].

In this way, specimens with dimensions of $300 * 300 * 30 \mathrm{~mm}$ were made. After installation of fibers on the surface of the concrete in both simple epoxy and modified epoxy status, specimens were tested. According to ASTM D7522 standard test, the maximum vertical force exerted on the concrete surface, FRP and the epoxy adhesive was determined [40]. The surface at which the failure occurs represented the weakest surface among the concrete, FRP and epoxy adhesive. These tests were separately performed for many samples of A (strength of concrete was C20) and B (strength of concrete was C40) as shown in Table 6. For simplification in samples naming, use following abbreviations: SC: simple concrete; RCFRP: reinforced concrete with FRP and RCFRPME: reinforced concrete with FRP using modified epoxy.

The pull-off test process, as shown in Fig. 4, is as follows; 1) using a drill for boring a $5 \mathrm{~cm}$ core; 2) connecting a rigid disk with high strength glue to the generated hole; and 3) applying a vertical tensile load. 
Considering the Fig. 5, it is clear that due to the tensile nature of applied force, the failure occurred in the concrete. Hence the connection properties had no significant effect based on this test, so, test method has been changed.

In second try, pull-off the test repeated on many specimens with a harder substrate including high strength grout and reinforced fibers. New specimens were made using NGS grouts plus polypropylene fibers and glass fibers. To gain more adhesion between FRP and concrete surface, first the specimen was blasted with sand and placed in acid container, then a wire brush was used to generate a smooth surface, as shown in Fig. 6a. Results were similar to the previous ones and the tension failure was observed in concrete was as shown in Table 7 and Fig. 6 b. Thus, test method should be changed again.

So, in third try, an alternate direct shear test was done on some specimens. FRP sheets are glued to metal sheets and stretched on both sides and tension force vs displacement were studied during testing. In this way, six specimens were made and tested again and the positive impact of nanoparticles in the resin has been approved as shown in Fig. 7. So, according to 4.2 section, this method led to acceptable results for the evaluation of resin and CNTs.
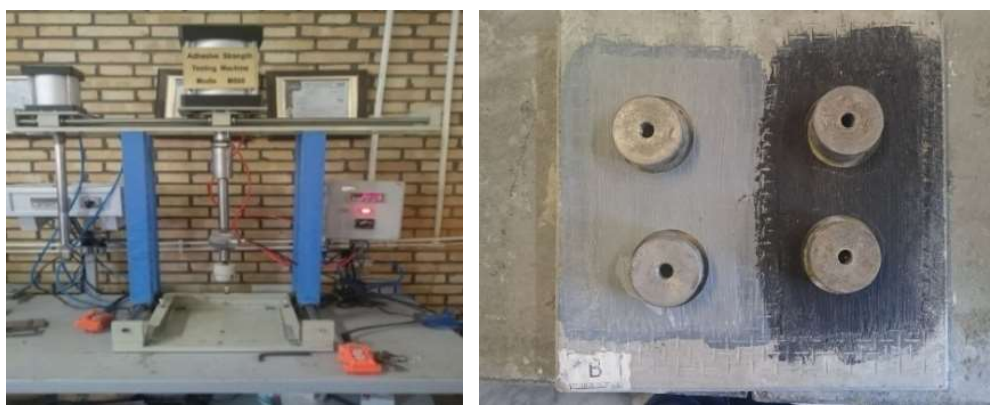

Fig. 4. Pull-off test setup and installed specimens
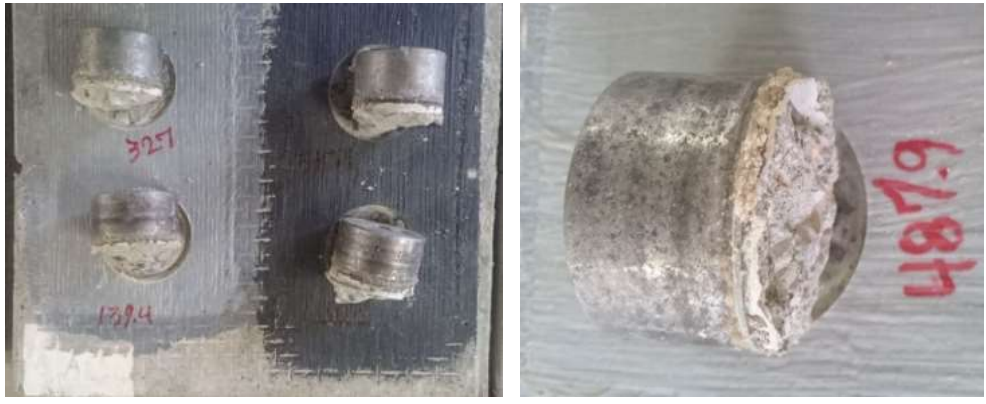

Fig. 5. Failure mode of the specimens in first pull-off test 

OF CONCRETE REINFORCED WITH FRP SHEETS
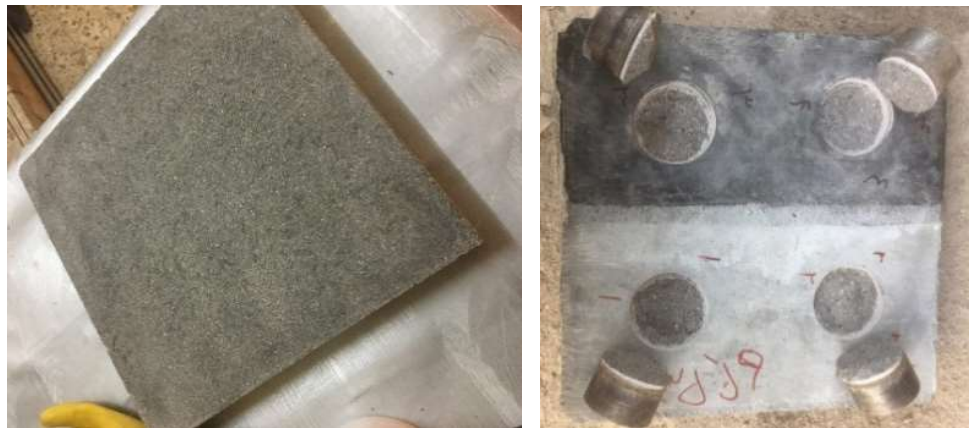

Fig. 6. High strength specimen and failure mode in second try test method

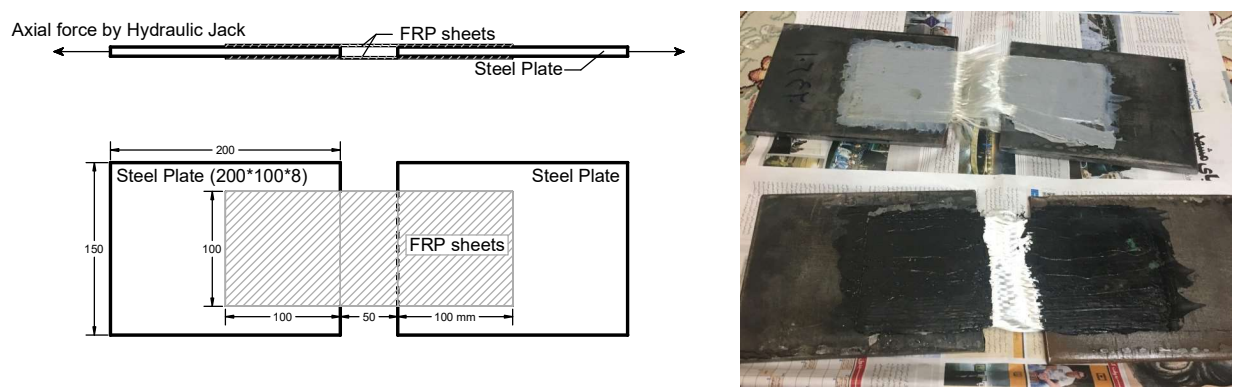

Fig. 7. Specimens dimensions in alternate direct shear test (third try test) and failure of specimens in resin

Table 6. Pull-off test results

\begin{tabular}{|c|c|c|c|c|c|}
\hline No. & $\begin{array}{l}\text { Specimens } \\
\text { Type }\end{array}$ & $\begin{array}{l}\text { Concrete } \\
\text { Grade }\end{array}$ & $\begin{array}{l}\text { Failure } \\
\operatorname{load}(\mathrm{N})\end{array}$ & $\begin{array}{l}\text { Tensile strength } \\
(\mathrm{MPa})\end{array}$ & $\begin{array}{l}\text { Mean of tensile } \\
\text { strength }(\mathrm{MPa})\end{array}$ \\
\hline 1 & RCFRP* & $\mathrm{A}$ & 3469 & 1.77 & \multirow{2}{*}{1.86} \\
\hline 2 & RCFRP & $\mathrm{A}$ & 3822 & 1.95 & \\
\hline 3 & RCFRPME** $^{* *}$ & $\mathrm{~A}$ & 3744 & 1.91 & \multirow{2}{*}{1.85} \\
\hline 4 & RCFRPME & $\mathrm{A}$ & 3528 & 1.80 & \\
\hline 5 & RCFRP & B & 4390 & 2.24 & \multirow{2}{*}{2.14} \\
\hline 6 & RCFRP & $\mathrm{B}$ & 3979 & 2.03 & \\
\hline 7 & RCFRPME & $\mathrm{B}$ & 4410 & 2.25 & \multirow{2}{*}{2.19} \\
\hline 8 & RCFRPME & $\mathrm{B}$ & 4175 & 2.13 & \\
\hline
\end{tabular}

Note: All diameter specimens are $50 \mathrm{~mm}$

* reinforced concrete with FRP

** reinforced concrete with FRP using modified epoxy 
Table 7. Pull-off test results for the harder substrate (second try test)

\begin{tabular}{|l|l|l|l|l|}
\hline No. & Specimens Type & $\begin{array}{l}\text { Failure } \\
\text { load (N) }\end{array}$ & $\begin{array}{l}\text { Tensile strength } \\
(\mathrm{MPa})\end{array}$ & $\begin{array}{l}\text { Mean of Tensile } \\
\text { Strength (MPa) }\end{array}$ \\
\hline 1 & RCFRP & 5840 & 2.98 & \multirow{2}{*}{3.13} \\
\hline 2 & RCFRP & 6429 & 3.28 & \multirow{2}{*}{3.34} \\
\hline 3 & RCFRPME & 6076 & 3.10 & \\
\hline 4 & RCFRPME & 6233 & 3.18 & \\
\hline
\end{tabular}

Note: All diameter specimens are $50 \mathrm{~mm}$

\subsection{Compression Strength Test}

Compressive strength test is a mechanical test measuring the maximum amount of compressive load a material can bear before fracturing and it is one of the most important engineering properties for designers, especially for concrete specially columns under axial forces. The compression strength specimens have been determined according to ISO 4012:1978. So, 15 cylindrical specimens $(200 * 100 \mathrm{~mm})$ and 15 cubic specimens $(100 * 100 \mathrm{~mm})$ were prepared as shown Figs. 1 and 8.

All specimens were tested using high capacity hydraulic jack in the laboratory and the strength compression was taken into account and the results are presented in 4.3 section.

\subsection{Flexural Test}

The effect of CNTs on the bending strength were evaluated for fine-grained concrete samples. Specimens were in small scale $(50 \times 50 \times 160 \mathrm{~mm})$ based on the weighted concrete mix; 1.0-part cement and 2.75 parts of sand were used.

To determine bending strength, specimen's size and laboratory conditions were used according to standard ASTM C348. Simply supported fine-grained concrete beams with section of $40 * 40 \mathrm{~mm}$ and length of $9.6 \mathrm{~cm}$ were made. Flexural strength tests were performed on 3 of each item include SC, RCFRP, and RCFRPME specimens under low-speed loading as shown in Fig. 9 and the results are presented in following section.
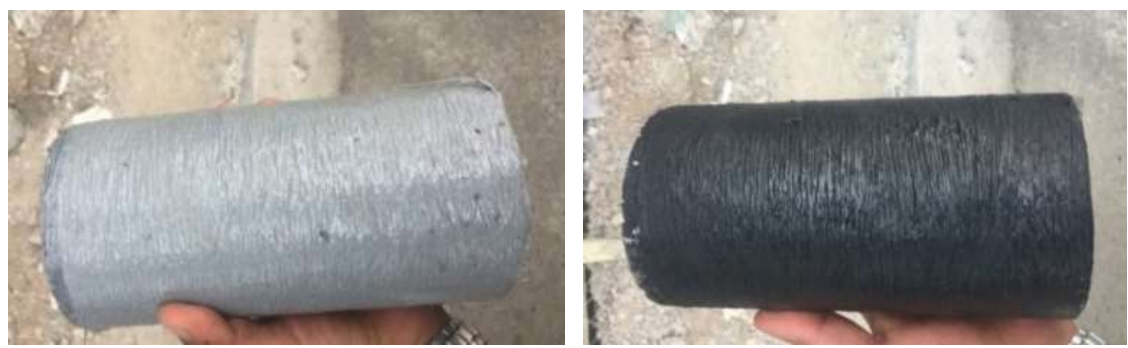

Fig. 8. Specimens for compression strength test: a) RCFRP (left), b) RCFRPME (right) 

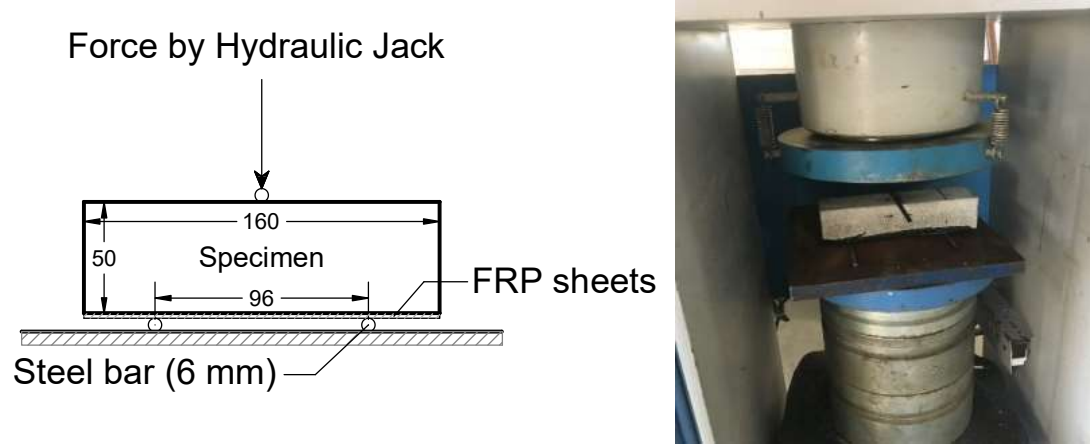

Fig. 9. The fine-grained concrete under the flexural strength test

\section{RESULTS AND DISCUSSION}

\subsection{Optimal Percentage of CNT Result}

The best weighted percentage of CNT was determined by shear test, because, this value can reduce or increase bond-slip. For this purpose, four observed percentages were examined and the best percentage was estimated for next laboratory tests. Preliminary tests showed that 4 to $4.5 \mathrm{wt} \%$ of CNT is an optimal mixture percentage for enhancing the bonding strength. Fig. 10 shows that approximately $4.2 \%$ of CNT can be an optimal mixture percentage based on second-order equation fitting curve. It should be noted that the optimal percentage depends on the type of resin, concrete surface specification and the type of sample, but since the materials and samples are widely used commercially, it can be used as a practical reference for strengthening. So, all specimens of RCFRPME made reasonably well with 4.2 percent of CNTs for pull-off, compressive and flexural tests.

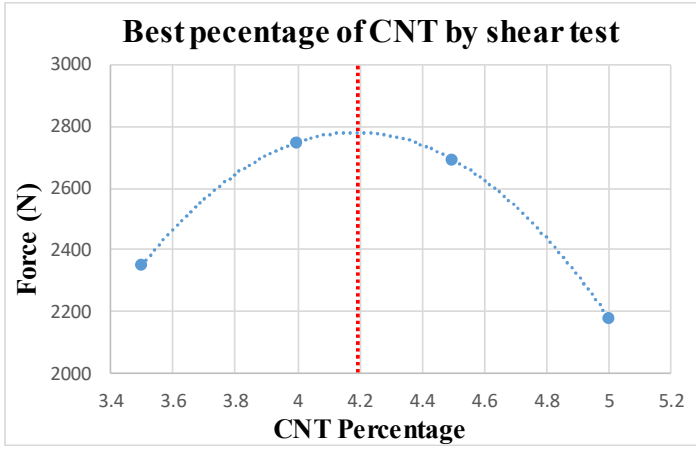

Fig. 10. Shear test results to obtain the optimal mixture percentage of CNT 


\subsection{Pull-off Results}

Pull-off test was performed for adhesion FRP fiber and concrete surface according to ASTM C1583 using the third test method as shown in Fig.7. It is noted that, the tensile base tests showed that the failure occurred in concrete and it couldn't be the basis for judging the adhesive used and contact materials as shown in Figs. 5 and 6 . In contrast, the shear base experiments were able to produce reasonable results to show the behavior of the adhesive and the nanomaterials performance. Fig. 11 shows that the ultimate shear strength of specimens is constant, but initial stiffness and ductility increased sharply and approximately $100 \%$ was noticeable. The results show that the behavior and deformation of laboratory samples are quite similar and the stiffness increases by about 2.1 times and the ductility by more than 2.05 times. So it can be guaranteed that the performance of resins improves inevitably using nanoparticles which leads to an apparent increase in behavioral properties, especially for strengthened FRP members/beams under tension or bending forces. It should be noted that deviations at the beginning of load curves in Fig. 11 are related to instrumental errors and primary unsteadiness.

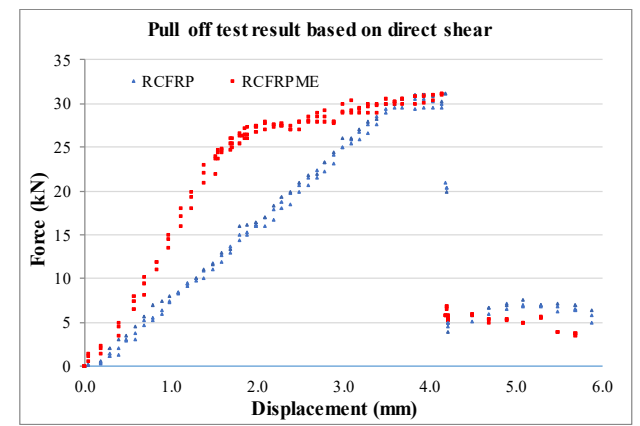

Fig. 11. Direct shear test result for RCFRP and RCFRPME

\subsection{Compressive Strength Results}

Based on the compression tests, compressive strength values were obtained for prepared specimens and presented in Table 8 and Fig. 12. The results show a significant increase in compressive strength after utilizing CNTs. Fig. 12 shows RCFRP and RCFRPME increase strength compression at least 59\% and $79 \%$ in comparison with $\mathrm{SC}$, respectively. So, the CNT application shows a $13 \%$ improvement in compressive strength.

Obviously, with increasing the diameter of the samples (same columns), the rate of increase in compressive strength can vary and so additional studies are needed. 

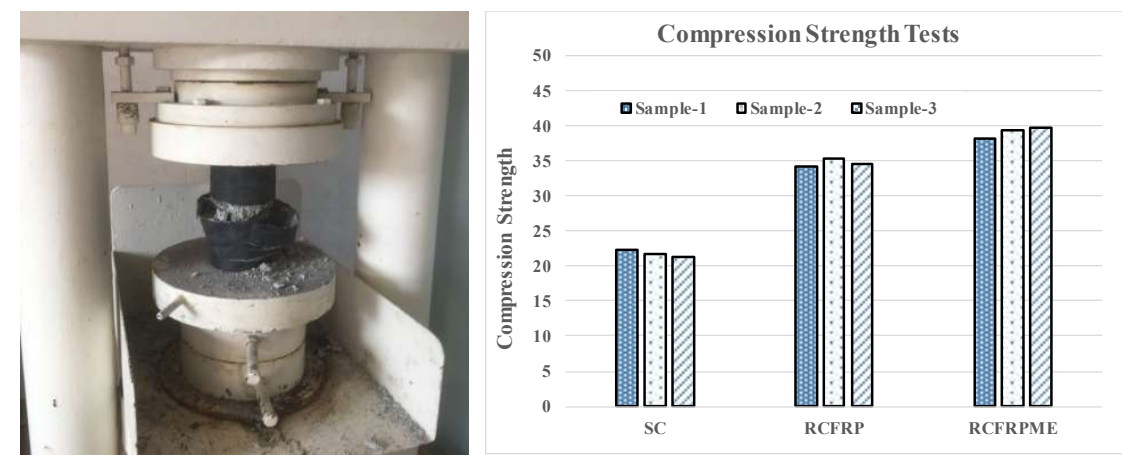

Fig. 12. The compression strength in desired concrete specimens

\subsection{Flexural Strength Results}

Flexural test indirectly evaluates the tensile strength of concrete. Here, it tests the ability of unreinforced concrete beam and RCFRP and RCFRPME beams to withstand failure in bending. Although, due to laboratory limitations, the specimens were made with small dimensions, the results showed the noticeable effect of nanomaterials in both flexural strength and failure mechanism.

Table 9 and Fig. 13 show that the mean flexural strength in SC is $4.88 \mathrm{MPa}$, so for RCFRP specimens, it increased about 4.28 times. Also, flexural strength increased from $27.96 \mathrm{MPa}$ to $30.34 \mathrm{MPa}$ averagely and equaled to $12.6 \%$ for RCFRPME. So, an increase in flexural strength is also confirmed up to $13 \%$.

As shown in Fig. 14, considering the sample type, specimens experienced different failure modes. SC specimens failed in the middle with a vertical tension crack, but RCFRP and RCFRPME specimens have a different trend. For RCFRP in the tension side of the middle beam, tension-shearing cracks extended towards the supports, then high tension-shear cracks happened in FRP resins and therefore FRP fibers have separated from the concrete; crashing also occurred in the compression side.

In RCFRPME, after crashing in the compression side due to better adhesion and higher shear strength in the resin, due to increase bonding capacity, the cracks extended in two ways and angled toward the supports and fracture surfaces were expanded. In fact, "strut and tie" situation can be seen in a compression-tension triangular in the concrete and FRP as shown in Fig. 14. 

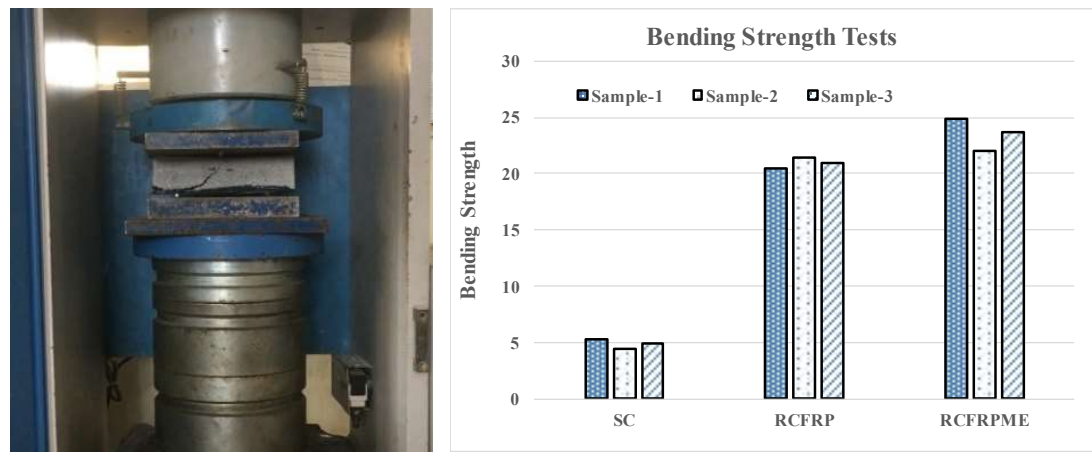

Fig. 13. Flexural strength for different specimens
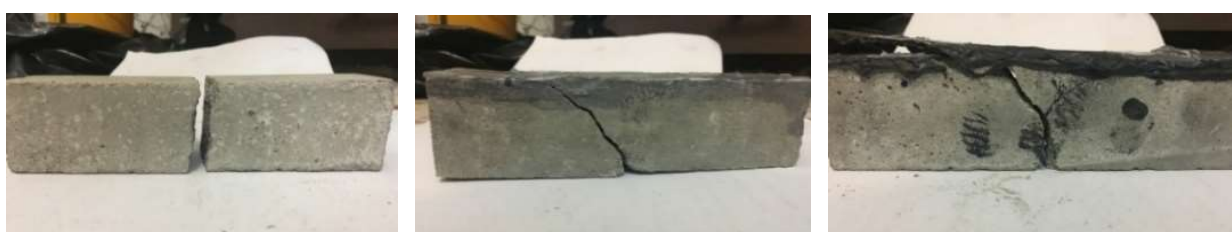

Fig. 14. Failure in the bending tests of SC, RCFRPSE, RCFRPME specimens, left to right, respectively

Table 8. Compression strength test results

\begin{tabular}{|c|c|c|c|c|}
\hline No. & $\begin{array}{l}\text { Specimen size } \\
(\mathrm{mm})\end{array}$ & $\begin{array}{l}\text { Failure load } \\
(\mathrm{kN})\end{array}$ & $\begin{array}{l}\text { Compression } \\
\text { strength }(\mathrm{MPa})\end{array}$ & $\begin{array}{l}\text { Mean of compression } \\
\text { strength }(\mathrm{MPa})\end{array}$ \\
\hline 1 & $101 * 202$ & 178.92 & 22.3 & \multirow{3}{*}{21.8} \\
\hline 2 & $102 * 201$ & 177.11 & 21.7 & \\
\hline 3 & $100 * 202$ & 168.21 & 21.4 & \\
\hline 4 & $103 * 200$ & 284.34 & 34.1 & \multirow{3}{*}{34.7} \\
\hline 5 & $104 * 201$ & 299.57 & 35.3 & \\
\hline 6 & $103 * 199$ & 288.33 & 34.6 & \\
\hline 7 & $103 * 200$ & 318.01 & 38.2 & \multirow{3}{*}{39.1} \\
\hline 8 & $104 * 202$ & 334.62 & 39.4 & \\
\hline 9 & $102 * 201$ & 324.27 & 39.7 & \\
\hline
\end{tabular}



OF CONCRETE REINFORCED WITH FRP SHEETS

Table 9. Flexural strength test results

\begin{tabular}{|l|l|l|l|l|}
\hline No. & $\begin{array}{l}\text { Specimen size } \\
(\mathrm{mm})\end{array}$ & $\begin{array}{l}\text { Failure load } \\
(\mathrm{N})\end{array}$ & $\begin{array}{l}\text { Bending strength } \\
(\mathrm{MPa})\end{array}$ & $\begin{array}{l}\text { The mean Bending } \\
\text { strength }(\mathrm{MPa})\end{array}$ \\
\hline 1 & $161 * 40 * 40$ & 2353 & 5.29 & \multirow{2}{*}{4.88} \\
\hline 2 & $162 * 41 * 40$ & 1981 & 4.46 & \\
\hline 3 & $161 * 40 * 40$ & 2178 & 4.90 & \multirow{2}{*}{20.91} \\
\hline 4 & $159 * 40 * 41$ & 9777 & 20.43 & \\
\cline { 1 - 4 } 5 & $162 * 41 * 41$ & 10237 & 21.39 & \multirow{2}{*}{23.53} \\
\hline 6 & $163 * 40 * 40$ & 9301 & 20.93 & \\
\hline 7 & $161 * 40 * 40$ & 11080 & 24.93 & \\
\hline 8 & $163 * 41 * 41$ & 10532 & 22.01 & \\
\hline 9 & $159 * 41 * 40$ & 10518 & 23.67 & \\
\hline
\end{tabular}

\section{CONCLUSION}

In order to determine risk/vulnerability reduction, rehabilitation or retrofitting of the existing structures is suggested as one of the most effective ways. In this way, FRP sheets are used in retrofitting the concrete structures that in recent years has been considered more significantly. Also the development of nano-materials has created innovative raw materials used in the building construction. So, extensive researches are carried out on sheets, materials and nano-materials, connections and economical construction methods. Studies have shown that the overall performance of concrete members with FRP is strongly affected by adhesive resins, especially in ultimate loads.

In this paper as an experimental research, the effect of adding nano-carbons to resin on the mechanical properties of concrete specimens was studied. So, the impact of CNTs on the ultimate axial, shear, and flexural strength were estimated. The following conclusions are obtained based on experimental results:

1. For practical purposes, the optimal mixture percentage of CNT is approximately $4.2 \%$.

2. Using FRP, the compression strength increased by $60 \%$ and adding CNTs to an FRP adhesive resin increased the strength up to $79 \%$.

3. In addition to the broader failure surface, adding CNTs, leads to about $13 \%$ increase in flexural strength.

4. Shear tests results showed that the initial stiffness and ductility significantly enhanced up to $200 \%$.

Finally, it can be noted that although using carbon nanoparticles is accompanied by implementing difficulties and raising costs, it is still applicable and useful due to improvements in system performance. 


\section{REFERENCES}

1. Banaei pour, A and Tavakolizadeh, MR 2015. Effect of change in fiber direction on the compression behavior of confined concrete reinforced with FRP. Seventh national concrete conference of Iran, Tehran, Iran.

2. Kabir, MZ, Aladdin, S and Hijab, H 2013. Evaluating the performance of reinforced concrete frame by FRP polymer covers under cyclic loads. Civil Engineer magazine. Issue 3.

3. Nakaba, K, Kanakubo, T, Furuta, T and Yoshizawa, H 2001. Bond behavior between fiber-reinforced polymer laminates and concrete. ACI Structural Journal, vol. 98 (3), p.359-367.

4. Teng, JG and Lam, L 2002. Compressive Behavior of Carbon Fiber Reinforced Polymer-Confined Concrete in Elliptical Columns. Journal of Structural Engineering, vol. 128 (12).

5. Park, T W Na, UJ, Chung, L and Feng, MQ 2008. Compressive behavior of concrete cylinders confined by narrow strips of CFRP with spacing. Composites: Part B, vol. 39, p. 1093-1103.

6. Diego, A, de Arteaga, A, Fernández, J, Perera, R and Cisneros, D 2015. Behaviour of FRP confined concrete in square columns. Materiales de Construcción, vol. 65.

7. Dong, JF, Wang, QY and Guan, ZW 2012. Structural behaviour of RC beams externally strengthened with FRP sheets under fatigue and monotonic loading, Engineering Structures, p. 24-33.

8. Mahal, MSM 2015. Fatigue Behaviour of RC beams Strengthened with CFRP, Analytical and Experimental investigations. Ph.D Thesis, Department of Civil, Environmental and Natural Resources Engineering Luleå University of Technology, Sweden.

9. Ferrari, VJ, Hanai, JB and Souza, RA 2013. Flexural strengthening of reinforcement concrete beams using high performance fiber reinforcement cement-based composite (HPFRCC) and carbon fiber reinforced polymers (CFRP), Construction and Building Materials, p. 485-498.

10. Cristina, L, Firmo, JP, Correia, JR and Tiago, C 2013. Fire protection systems for reinforced concrete slabs strengthened with CFRP laminates. Construction and Building Materials, p. 324-333.

11. Faruqi, M, Escobedo, G, Sun, D and Sai, J 2013. Research and design guidelines for the construction of fiber-reinforced polymer reinforced concrete structures under fire exposure: A brief review. Journal of Reinforced Plastics and Composites, vol. 32 (17), p. 1302-1309.

12. Naderi, $M$ and Esmayizade, S 2013. The ultimate strength of concrete beams strengthened by CFRP fabric and laminates at high freezing temperatures. Amir Kabir Journal of Civil Engineering, vol. 48, p. 39-52.

13. Kheireddine, B, Ahmed, EA, El-Gamal, S and Benmokrane, B 2011. Testing of full-scale concrete bridge deck slabs reinforced with fiber-reinforced 
polymer (FRP) bars. Construction and Building Materials, vol. 25 (10), p. 3956-3965.

14. Zheng, Y, Li, C and $\mathrm{Yu}, \mathrm{G}$ 2012. Investigation of structural behaviors of laterally restrained GFRP reinforced concrete slabs. Composites Part B, vol. 43 (3), p. 1586-1597.

15. Zheng, Y, Yu, G and Pan, Y 2012. Investigation of ultimate strengths of concrete bridge deck slabs reinforced with GFRP bars. Construction and Building Materials, p. 482-492.

16. Wilson, MA, Raguse, B, Kannangara, K, Smith, G and Simmons, M 2014. Nanotechnology: basic science and emerging technology. Publisher: ReadHowYouWant.com.

17. Golabchi, M, Taghizadeh, K and Soroushnia, E 2011. Nanotechnology in architecture and civil engineering. Published by University of Tehran Press.

18. Rosso, P, Ye, L, Friedrich, K and Sprenger, S 2006. A toughened epoxy resin by silica nanoparticle reinforcement. Journal of Applied Polymer Science, vol. 100 (3), p. 1849-1855.

19. Tsai, JL and Cheng, YL 2009. Investigating silica nanoparticle effect on dynamic and quasi-static compressive strengths of glass fiber/epoxy nanocomposites. Journal of Composite Materials, vol. 43 (25), p. 3143-3155.

20. Godara, A, et al. 2009. Influence of carbon nanotube reinforcement on the processing and the mechanical behavior of carbon fiber/epoxy composites. Carbon Journal, vol. 47 (12), p. 2914-2923.

21. Greef, N, de Gorbatikh, L, Godara, A, Mezzo, L, Lomov, SV and Verpoest, I 2011. The effect of carbon nanotubes on the damage development in carbon fiber/epoxy composites. Carbon Journal, vol. 49 (14), p. 4650-4664.

22. Phong, NT, Gabr, MH, Okubo, K, Chuong, B and Fujii, T 2013. Improvement in the mechanical performances of carbon fiber/epoxy composite with addition of nano-(Polyvinyl alcohol) fibers. Composite Structures, vol. 99, p. 380-387.

23. He, H, Zhang, Z, Wang, J and Li, K 2013. Compressive properties of nanocalcium carbonate/epoxy and its fibre composites. Composites Part B, vol. 45 (1), p. 919-924.

24. Shirkavand Hadavand, B, Mahdavi Javid, K and Gharagozlou, M 2013. Mechanical properties of multi-walled carbon nanotube/epoxy polysulfide nanocomposite. Materials and Design, vol. 50, p. 62-67.

25. Sánchez, M, Campo, M, Jiménez-Suárez, A and Ureña, A 2013. Effect of the carbon nanotube functionalization on flexural properties of multiscale carbon fiber/epoxy composites manufactured by VARIM. Composites Part B, vol. 45 (1), p. 1613-1619. 
26. Liu, F, Deng, S and Zhang, J 2017. Mechanical Properties of Epoxy and Its Carbon Fiber Composites Modified by Nanoparticles. Journal of Nanomaterials, p. 1-9.

27. Zhou, Y, Gou, M, Zhang, F, Zhang, S and Wang, D 2013. Reinforced concrete beams strengthened with carbon fiber reinforced polymer by friction hybrid bond technique: Experimental investigation. Materials and Design, vol. 50, p. $130-139$.

28. Diab, HM and Farghal, O A 2014. Bond strength and effective bond length of FRP sheets/plates bonded to concrete considering the type of adhesive layer. Composites: Part B, vol. 58, p. 618-624.

29. Korayem, AH, Li, CY, Zhang, QH, Zhao, ZL and Duan, WH 2015. Effect of carbon nanotube modified epoxy adhesive on CFRP-to-steel interface. Composites Part B, vol. 79, p. 95-104.

30. Irshidat, MR and Al-Saleh, MH 2016. Effect of using carbon nanotube modified epoxy on bond-slip behavior between concrete and FRP sheets. Construction and Building Materials, vol. 105, p. 511-518.

31. Varastehpour, H and Eskenazy, A R 2014. Increasing the bending capacity of concrete beams, using the fiberglass composites. Seventh national concrete conference of Iran, Tehran.

32. GangaRao, VS, Taly, N and Vijay, PV 2007. Reinforced concrete design with FRP composites. Taylor \& Francis Group, LLC.

33. ISO 4012/1978 1978. Concrete-Determination of compressive strength of test specimens. Geneva.

34. ASTM C348-02 2002. Standard test method for flexural strength of hydraulic cement mortars. American Society for Testing and Materials.

35. ACI 440.2R-08 2008. Guide for the Design and Construction of Externally Bonded FRP Systems for Strengthening Concrete Structures.

36. ASTM D3039/D3039M-17 2017. Standard Test Method for Tensile Properties of Polymer Matrix Composite Materials.

37. Narang, J and Pundir, CS 2018. Current and Future Developments in Nanomaterials and Carbon Nanotubes, Introduction to Carbon Nanomaterials. Bentham Science Publishers, vol. 1.

38. Mismiran, A Shahawy, M Nanni, A and Karbhari, V 2004. NCHRP report 514, Bonded repair and Retrofit of Concrete Structures Using FRP Composites. Transportation Research Board.

39. ASTM C1583/C1583M-13 2013. Standard Test Method for Tensile Strength of Concrete Surface and the Bond Strength or Tensile Strength of Concrete Repair and Overlay Materials by Direct Tension (Pull-off Method).

40. ASTM D7522 / D7522M-15 2015. Standard Test Method for Pull-Off Strength for FRP Laminate Systems Bonded to Concrete Substrate.

Editor received the manuscript: 02.02.2021 